\title{
Petrobactin, a siderophore produced by Alteromonas, mediates community iron acquisition in the global ocean
}

\author{
Lauren E. Manck $\mathbb{D}^{1 凶}$, Jiwoon Park ${ }^{2}$, Benjamin J. Tully $\mathbb{D D}^{3}$, Alfonso M. Poire ${ }^{4}$, Randelle M. Bundy (iD ${ }^{2}$, Christopher L. Dupont (iD ${ }^{4,5,6}$ and \\ Katherine A. Barbeau (iD ${ }^{1}$ \\ (c) The Author(s) 2021 \\ It is now widely accepted that siderophores play a role in marine iron biogeochemical cycling. However, the mechanisms by which \\ siderophores affect the availability of iron from specific sources and the resulting significance of these processes on iron \\ biogeochemical cycling as a whole have remained largely untested. In this study, we develop a model system for testing the effects \\ of siderophore production on iron bioavailability using the marine copiotroph Alteromonas macleodii ATCC 27126. Through the \\ generation of the knockout cell line $\triangle a s b B:: \mathrm{km}^{\mathrm{r}}$, which lacks siderophore biosynthetic capabilities, we demonstrate that the \\ production of the siderophore petrobactin enables the acquisition of iron from mineral sources and weaker iron-ligand complexes. \\ Notably, the utilization of lithogenic iron, such as that from atmospheric dust, indicates a significant role for siderophores in the \\ incorporation of new iron into marine systems. We have also detected petrobactin, a photoreactive siderophore, directly from \\ seawater in the mid-latitudes of the North Pacific and have identified the biosynthetic pathway for petrobactin in bacterial \\ metagenome-assembled genomes widely distributed across the global ocean. Together, these results improve our mechanistic \\ understanding of the role of siderophore production in iron biogeochemical cycling in the marine environment wherein iron \\ speciation, bioavailability, and residence time can be directly influenced by microbial activities.
}

The ISME Journal (2022) 16:358-369; https://doi.org/10.1038/s41396-021-01065-y

\section{INTRODUCTION}

Iron (Fe) is an essential micronutrient for marine microorganisms, serving as a cofactor in enzymes facilitating fundamental processes such as photosynthesis, respiration, and nitrogen fixation. However, in oxygenated seawater at $\mathrm{pH} \sim 8$, inorganic dissolved iron is most thermodynamically stable in the form of Fe (III) hydroxide complexes. These hydroxide complexes have the tendency to be scavenged by sinking particulate matter and are in equilibrium with Fe(III) oxyhydroxide particulates which are characterized by low solubility [1]. Coupled with enhanced biological uptake in the surface ocean, this results in extremely low dissolved iron concentrations in most regions of the global ocean and limits primary production by photoautotrophs in more than one-third of the surface ocean [2].

With a significant iron requirement [3-5], marine heterotrophic bacteria are also impacted by this iron scarcity and have therefore developed multiple pathways for acquiring sufficient iron from their environment [6]. One such pathway is through the production, exudation, and uptake of siderophores. Siderophores are low-molecular-weight compounds (500-1500 Da) secreted from a cell that binds strongly to iron and is subsequently acquired through outer membrane TonB dependent transporters (TBDTs) in Gram-negative bacteria. The capacity for siderophore biosynthesis by cultivated marine bacteria has been recognized now for several decades [7-14], and suites of siderophores with various chemical moieties have been isolated from cultured marine representatives [15]. The increasing availability of marine bacterial genomes and metagenomes has allowed for a more comprehensive view of the capacity for siderophore production and uptake by marine bacteria [6]. In addition, it has been demonstrated that eukaryotic phytoplankton also have the ability to utilize siderophore-bound iron [4, 16-18]. Electrochemical measurements have widely detected strong iron-binding ligands in seawater, and a portion of this strong ligand pool is likely comprised of siderophores. More recently, several structural classes of siderophores have been isolated directly from seawater [19-22].

Given these observations, it is now widely accepted that siderophores play a role in iron acquisition and cycling in the marine environment. However, despite recent advances in our understanding of the production and distribution of siderophores in the marine environment, a gap has remained in our ability to experimentally test hypotheses regarding the functional role of siderophores in the marine biogeochemical iron cycle. Siderophores comprise one fraction of a diverse pool of organic ligands that bind over $99 \%$ of the dissolved iron in seawater and largely control the bioavailability and residence time of dissolved iron in the oceans [23]. Due to their high binding affinities for iron,

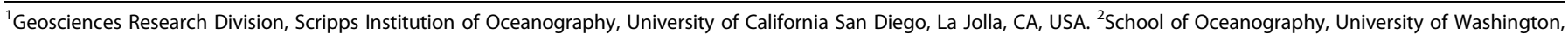

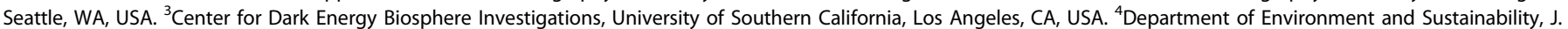

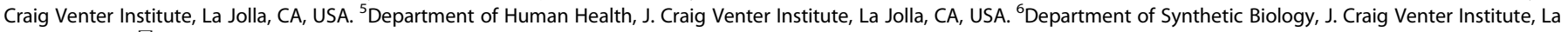
Jolla, CA, USA. ${ }^{凶}$ email: lauren.manck@flbs.umt.edu 
siderophores have the potential to capture iron from many sources and sequester it in very specific forms, including the ability to solubilize particulate forms of iron [24-29]. However, the various iron sources from which siderophores can effectively obtain iron to support bacterial growth in the marine environment have not been experimentally determined, leaving open questions regarding their role in marine microbial iron acquisition as well as their influence on overall iron cycling. Accomplishing this will be an important step in understanding and modeling the global iron biogeochemical cycle.

In recent work, the marine copiotroph Alteromonas macleodii ATCC 27126 has been characterized as a siderophore producer $[30,31]$, and a suite of putative iron transporters in this strain has been identified by transcriptomic analysis of iron-limited cultures [31]. The genus Alteromonas is prevalent in oceanic waters [32], and members have been found to become highly abundant in environments enriched in organic matter and nutrients [33-37]. In addition, in the iron-limited waters of the Southern Ocean, members of Alteromonadales displayed the highest expression of genes related to iron metabolism on a per-cell basis while comprising only $1-2 \%$ of the total prokaryotic population [38]. These previous studies suggest that this genus has the potential to disproportionately affect the processing of organic matter and its associated macro- and micronutrients [39]. In the work presented here, we aim to utilize the marine copiotroph $A$. macleodii ATCC 27126 as an environmentally relevant model organism in order to provide an improved framework, based on experimental evidence, for the role of siderophore production in iron acquisition and biogeochemical cycling in the marine environment. We accomplish this first by comparing the growth of wild-type (WT) A. macleodii ATCC 27126 to a generated knockout mutant, $\triangle a s b B:: \mathrm{km}^{\mathrm{r}}$ which lacks siderophore biosynthetic capabilities, on multiple sources of iron in culture. We then complement these culture studies with analytical and genomic field measurements in order to investigate the prevalence of petrobactin biosynthesis, the siderophore specifically produced by A. macleodii ATCC27126, across the global ocean.

\section{MATERIAL AND METHODS}

\section{Bacterial strains and growth conditions}

A. macleodii ATCC $27126 \mathrm{WT}$ and a generated $\triangle a s b B:: \mathrm{km}^{\mathrm{r}}$ line were used for all growth experiments. See below for details on the generation of the $\triangle a s b B:: \mathrm{km}^{\mathrm{r}}$ line. Escherichia coli Epi300 was used for conjugative plasmid delivery. A. macleodii was maintained on Marine Broth (MB) 2216 (BD Difco, Sparks, MD, USA) agar plates and liquid media at room temperature. E. coli was maintained on LB (BD Difco) agar plates and liquid media at $37^{\circ} \mathrm{C}$. Growth experiments as described below were conducted in PC + media prepared in artificial seawater $[31,40]$. Artificial seawater was utilized in order to reduce the concentration of background dissolved organic matter and the potential for competing for iron-binding ligands in solution. See the Supplemental Materials and Methods for the complete preparation of PC + media. Media was prepared and cultures were grown using appropriate aseptic techniques.

\section{Partial deletion and insertional inactivation of MASE_09715}

The A. macleodii ATCC $27126 \triangle a s b B:: \mathrm{km}^{\mathrm{r}}$ line was engineered via homologous recombination [41], targeting the disruption of MASE_09715 via the insertion of a kanamycin resistance cassette. The suicide plasmid pLEM01 was generated through a four-piece Gibson assembly [42] using a Gibson assembly master kit (New England Biolabs, Ipswich, MA, USA) following the manufacture's protocol (Table $\mathrm{S} 1$ ). The Bacillus subtilis $s a c B$ gene encoding levansucrase was included on the suicide plasmid opposite the homology arms and kanamycin resistance cassette (Fig. S1a), allowing for the selection of exconjugates with a double crossover at the insertion site. All polymerase chain reactions (PCR) for the generation of Gibson fragments were carried out using PrimeStar Max DNA polymerase (Takara Bio, Kusatsu, Japan). The desired assembly of pLEM01 was confirmed via PCR (Table S2, Fig. S1b). pLEM01 was transformed into chemically competent $E$. coli Epi300 cells containing the mobilization plasmid pTAMob followed by selection on LB plates with $50 \mu \mathrm{g} / \mathrm{mL}$ kanamycin. E. coli Epi300 containing both the pTA-Mob and pLEM01 plasmids was then mated overnight with A. macleodii ATCC 27126 WT on MB agar plates at $30^{\circ} \mathrm{C}$. Double crossover mutants were selected for through dilution plating onto $\mathrm{MB}$ plates with $50 \mu \mathrm{g} / \mathrm{mL}$ kanamycin and $5 \%$ sucrose. The high salinity of $\mathrm{MB}$ selected against the growth of $E$. coli during dilution plating. In addition, X-gal (Roche, Basel, Switzerland) was utilized at $260 \mu \mathrm{g} / \mathrm{mL}$ in order to visually distinguish $A$. macleodii from potentially contaminating $E$. coli colonies where the natural $\beta$-galactosidase activity of $A$. macleodii resulted in blue-stained cells. Individual exconjugant $A$. macleodii colonies were screened for the knockout phenotype on CAS plates [43] and positive phenotype colonies were further screened with PCR to confirm correct insertion (Table S2, Figure S2). The desired phenotype was also confirmed via analysis by liquid chromatography coupled to electrospray ionization mass spectrometry (LC-ESI-MS) of the culture supernatant from the mutant strain grown under iron limitation as described below.

\section{Siderophore characterization}

Siderophore production by ATCC 27126 was assessed by solid-phase extraction (SPE) of the siderophore from iron-limited ATCC 27126 culture supernatant followed by analyses via LC-ESI-MS. Both the ATCC 27126 WT and $\triangle a s b B:: \mathrm{km}^{\mathrm{r}}$ cell lines were grown in PC + media without any added iron source in order to induce iron limitation. After 8 hours of growth, cultures were terminated, and the culture supernatant was collected following filtration through a $0.2 \mu \mathrm{m}$ polycarbonate filter (Whatman, Maidstone, United Kingdom). The filtered supernatant was stored at $-20^{\circ} \mathrm{C}$ in the dark until analysis. See the Supplemental Materials and Methods for a detailed description of SPE and LC-ESI-MS conditions.

\section{Growth experiments with various iron sources common to the marine environment}

A. macleodii ATCC $27126 \mathrm{WT}$ and $\triangle a s b B:: \mathrm{km}^{\mathrm{r}}$ were maintained on MB 2216 agar and triplicate colonies of each were inoculated in $5 \mathrm{~mL}$ of liquid $\mathrm{MB}$ 2216 to initiate growth experiments. All liquid cultures were maintained in the dark at room temperature with shaking at $190 \mathrm{rpm}$. After $8 \mathrm{~h}$ of growth, $100 \mu \mathrm{L}$ of each liquid MB culture was then transferred to $5 \mathrm{~mL}$ of PC + media without any added iron source. The triplicate cultures were allowed to grow for $12 \mathrm{~h}$ in order to reach an iron-limited state. Finally, $100 \mu \mathrm{L}$ of each culture was then transferred to two $5 \mathrm{~mL}$ aliquots of fresh PC+ media, one with no added iron source (iron deplete control) and the second with an added iron source at a final total iron concentration of $5 \mu \mathrm{M}$, unless otherwise noted. Growth was tested on mineral-based iron sources (ferrihydrite colloids and Arizona Test Dust [ATD]), discrete iron-ligand complexes (ferrioxamine B, ferric citrate, heme, and cytochrome $c$ ), and heterogeneous sources of organically bound iron (Suwanee River Humic Acid [SRHA] reference material and phytoplankton lysate). Due to limited substrate availability, SRHA is the only substrate where the iron concentration was added at less than $5 \mu \mathrm{M}$ and concentrations varied across multiple SRHA treatments. See the Supplemental Materials and Methods for the specific preparation of each iron substrate tested. Cultures grown on $5 \mu \mathrm{M} \mathrm{FeCl}_{3}$ were used as iron-replete controls. Growth in each culture was monitored with optical density measurements at $600 \mathrm{~nm}$ (OD600) on a Spectronic 20 Genesys UV-VIS spectrophotometer. Maximum specific growth rates ( $\mu \mathrm{max}$ ) and carrying capacity $(K)$ were calculated using the growth rates package in R [44] and compared with an independent, two-tailed Student's $t$ test $(p<0.05)$.

\section{Field sampling and processing}

Samples were collected for in situ siderophore characterization throughout the Gradients 1.0 cruise on the R/V Ka'imikai-O-Kanaloa, between April 19 and May 4, 2016 at 8 stations along $158^{\circ} \mathrm{W}$, between $23.5^{\circ} \mathrm{N}$ and $37.3^{\circ} \mathrm{N}$. Ten to twenty liters of seawater were collected from discrete depths between the surface and $400 \mathrm{~m}$ with a trace metal clean rosette outfitted with Teflon-coated external spring Niskin bottles (Ocean Test Equipment, Fort Lauderdale, FL, USA) on a non-metallic line. Seawater was filtered through a $0.2 \mu \mathrm{m}$ Acropak 200 capsule filter (Pall, Port Washington, NY, USA) and then pumped at a flow rate of $18 \mathrm{~mL} / \mathrm{min}$ onto a Bond Elut ENV column (6 mL, $1 \mathrm{~g}$ resin) (Agilent Technologies, Santa Clara, CA, USA). The column was rinsed with two column volumes of Mili-Q water and stored at $-20^{\circ} \mathrm{C}$ until analysis via LC-ESI-MS. See the Supplemental Materials and Methods for a detailed description of SPE and LC-ESI-MS conditions. 


\section{Detecting petrobactin-like biosynthetic pathways in marine bacterial genomes}

A search for homologous biosynthetic gene clusters for petrobactin in uncultivated prokaryotes was conducted with the collection of metagenome-assembled genomes (MAGs) from the Tara Oceans dataset [45]. Search strategies aimed to identify the co-location of genes encoding non-ribosomal peptide synthase independent (NIS) siderophore synthases $(a s b A B)$ with those encoding 3-dehydroshikimate dehydratase (asbF). Together, these genes are diagnostic of biosynthetic pathways for petrobactin or petrobactin-derivatives [46-49] (Fig. 1). MAG assemblies were downloaded from NCBI (PRJNA391943) and protein-coding genes were detected with Prodigal (v2.6.3) [50]. The hidden Markov models for the conserved domains found within $a s b A B$ and $a s b F$ (pfam04183 and pfam01261, respectively) were searched against the detected proteincoding genes for each assembly using HMMER (v3.3) [51]. For assemblies where a positive hit for both pfam domains was detected, the colocalization of the two domains within the genome was manually determined. Pfam domains were then assigned to neighboring genes in order to determine the presence of a complete biosynthetic pathway.

The entire Tara Oceans metagenome dataset (reads representing 238 samples) was then competitively mapped to the identified MAGs with complete petrobactin-like biosynthesis pathways using Bowtie2 (v2.3.4.1) [52]. Results were filtered with BamM (v1.7.0) to remove reads that were less than $95 \%$ identical and had less than $75 \%$ alignment. Results were then converted to read count per contig using featureCounts (v1.5.3) [53] as implemented within BinSanity [54]. Read counts for individual MAGs were then normalized to reads per kbp genome per Gbp of metagenome (RPKM) for the filtered recruitment per sample. Identified MAGs that shared greater than $95 \%$ average nucleotide identity (ANI), as determined using FastANI (v1.3) [55] with a fragment length of $1500 \mathrm{bp}$, were considered to be members of the same species. As MAG assembly is semi-stochastic, MAGs of the same species will contain overlapping segments as well as unique segments. During competitive read recruitment, overlapping segments would split reads among MAGs of the same species while unique segments would not. In order to account for this, we aimed to evaluate the genome coverage of MAGS represented by a species-level environmental population in order to capture a comprehensive view of the distribution of the petrobactin-like biosynthetic gene cluster. To achieve this, the read counts per contig calculated above from a given sample for all MAGs of the same species were summed. To calculate an approximate RPKM value for the combined read counts, the length of the average complete species genome was estimated by taking the average of the length of each MAG multiplied by the corresponding percent completeness of that MAG, as calculated with CheckM [56].

\section{RESULTS \\ Petrobactin production by $A$. macleodii increases the bioavailability of specific iron sources}

Previous work has identified a putative NIS-type siderophore biosynthesis gene cluster in ATCC 27126 [30, 31] which was significantly upregulated under iron limitation [31]. Siderophore production was confirmed with a CAS assay $[30,31]$ and putatively identified as petrobactin based on sequence similarity of the biosynthetic gene cluster in ATCC 27126 to the characterized asbABCDEF operon in Bacillus anthracis [30] (Fig. 1). In the current work, LC-ESI-MS analysis of culture supernatant from iron-limited A. macleodii ATCC 27126 confirmed the siderophore produced by the WT strain as petrobactin. An $\mathrm{MS}^{1}$ peak at $719.361 \mathrm{~m} / \mathrm{z}$ was detected, corresponding to the expected $[\mathrm{M}+\mathrm{H}]^{+} \mathrm{m} / \mathrm{z}$ value for petrobactin $\left(\mathrm{C}_{34} \mathrm{H}_{50} \mathrm{~N}_{6} \mathrm{O}_{11}\right)$ from a comprehensive list of known siderophore structures [57] (Fig. S3a). The $\mathrm{MS}^{2}$ spectra collected from the $\mathrm{MS}^{1}$ peak at $719.361 \mathrm{~m} / \mathrm{z}$ further confirmed this identification with fragmentation peaks at 194, 282, 438, and $565 \mathrm{~m} / \mathrm{z}$ correspondings to previously reported $\mathrm{MS}^{2}$ spectra for petrobactin [47, 58] (Fig. S3C).

The $A$. macleodii ATCC $27126 \Delta a s b B:: \mathrm{km}^{\mathrm{r}}$ cell line was engineered via the insertional inactivation of MASE_09175 (putative $a s b B$ within the biosynthetic gene cluster of ATCC 27126, Fig. 1) with a kanamycin resistance cassette (Fig. S2). The disruption of MASE_09175 completely eliminated the production of petrobactin in the $\triangle a s b B:: \mathrm{km}^{r}$ cell line as determined with a CAS assay (Fig. S4) and LC-ESI-MS analysis of culture supernatant from iron-limited cells (Fig. S3b).

The growth of the $A$. macleodii ATCC 27126 WT strain was then compared to that of the $\triangle a s b B:: \mathrm{km}^{\mathrm{r}}$ mutant strain on a range of iron sources common to the marine environment in order to determine the effects of siderophore production on iron bioavailability. Ferrihydrite colloids and ATD were utilized as representatives of lithogenic iron sources to the marine environment. EDTA-bound iron and SRHA reference material served as model substrates for weakly complexed iron-ligand pools. Ferrioxamine B, ferric citrate, heme, cytochrome $c$ (a heme protein with a covalently bound heme prosthetic group), and phytoplankton lysate represented dominant sources of biogenically complexed iron. With the exception of the SRHA treatments, all iron sources were added at a final total iron

A. macleodii ATCC 27126
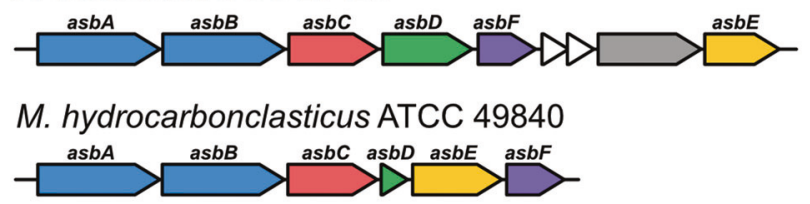

\section{B. anthracis Sterne}
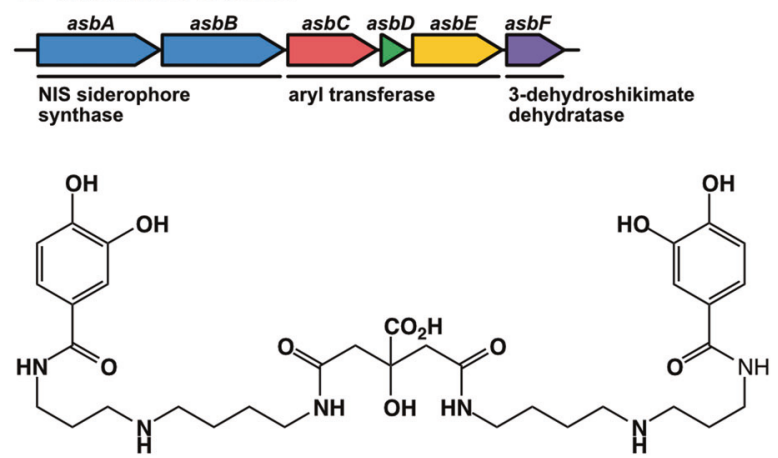

Fig. 1 The biosynthetic gene clusters of the known petrobactin producers A. macleodii ATCC 27126, M. hydrocarbonclasticus ATCC 49840, and $B$. anthracis Sterne are depicted with the petrobactin structure below. Genes are colored and labeled according to sequence similarity with the well-characterized $B$. anthracis biosynthetic gene cluster. A PepSY domain-containing gene (gray) and genes encoding two hypothetical proteins (white) are also present within the A. macleodii ATCC 27126 biosynthetic gene cluster. 
concentration of $5 \mu \mathrm{M}$. The results of these experiments (growth curves and calculated growth rates and culture carrying capacities) are displayed in Figs. 2, S5, S6, and S7. Growth on $5 \mu \mathrm{M} \mathrm{FeCl}_{3}$ was used as a control for replete iron conditions, and both the WT and $\triangle a s b B:: \mathrm{km}^{\mathrm{r}}$ strains grew equally well under these conditions (Figs. 2a, $\mathrm{S} 5 \mathrm{a}$, and $\mathrm{S7a}$ ). Cultures without the addition of any iron source were used as controls for iron deplete conditions.

In order to test the role that petrobactin production plays in the acquisition of iron from colloidal and particulate minerals, the growth of the WT and $\triangle a s b B:: \mathrm{km}^{r}$ strains was compared on ferrihydrite colloids synthesized with both 5 and $60 \mathrm{~min}$ of heating, the latter of which is less labile [59]. Growth was also tested on ATD in both its unmodified form as well as following a
Berger leach, again the latter of which is expected to contain less labile iron. ATD is a commercially available mineral dust material that is well characterized for its trace metal content and is being assessed as a consensus reference material for aerosol studies $[60,61]$. Operationally, the Berger leach is utilized to remove the bioavailable fraction of iron from particulates via a reducing weak acid leach [62]. The total iron concentration of each of these treatments in culture was held constant at $5 \mu \mathrm{M}$. The WT strain grew at a faster rate and achieved higher cell densities compared to that of the $\triangle a s b B:: \mathrm{km}^{\mathrm{r}}$ strain on each of these mineral iron sources (Figs. 2b, S5b, and S7b). When grown on ferrihydrite colloids synthesized under 5 min of heating, the maximum specific growth rate of the $\Delta a s b B:: \mathrm{km}^{\mathrm{r}}$ strain was only slightly less than
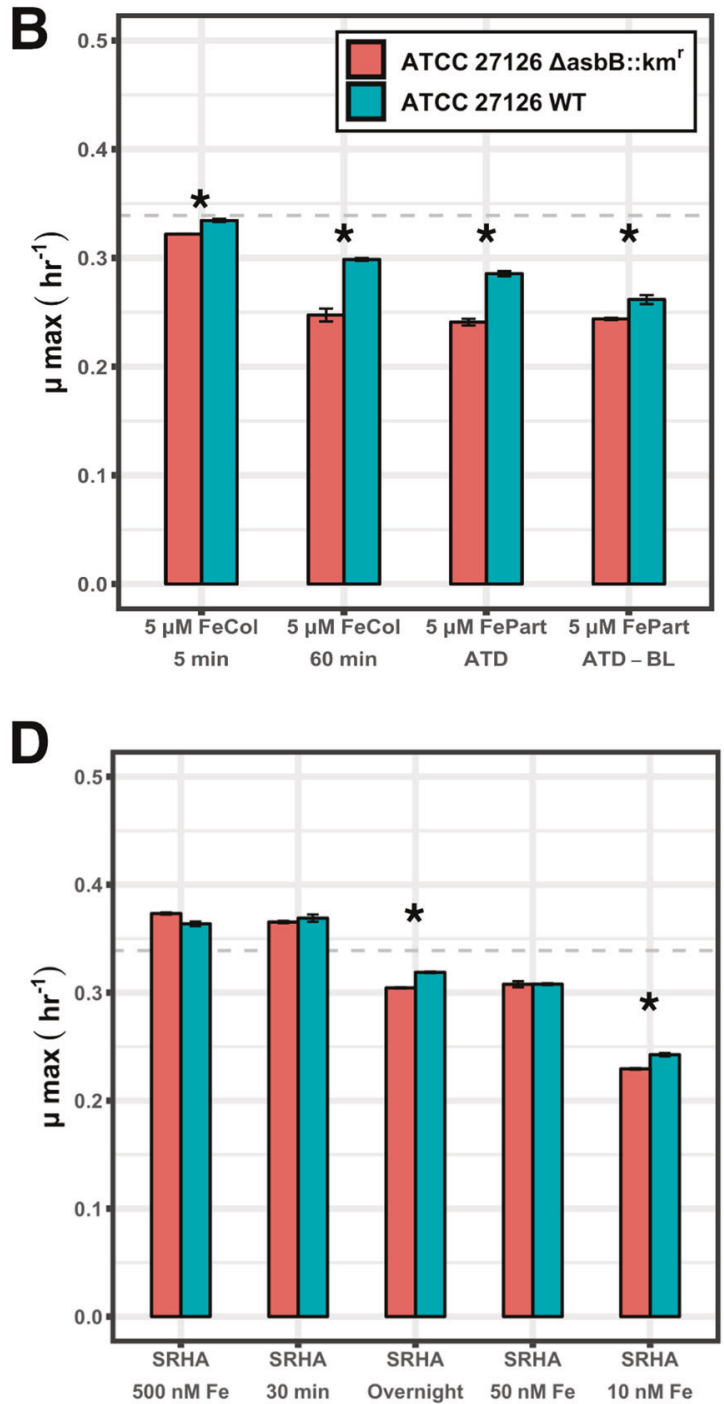

Fig. 2 Maximum specific growth rates ( $\mu$ max) of the $A$. macleodii ATCC 27126 WT and $\Delta a s b B: k^{r}{ }^{r}$ strains on tested iron sources. Conditions marked with an asterisk indicate a statistically significant difference between the WT and $\Delta a s b B:: k^{r}{ }^{r}$ strains (independent, twotailed $t$ test, $p<0.05$ ). Error bars represent the standard deviation of measurements from biological triplicates. A horizontal dashed line is a reference point for the observed growth rate of $A$. macleodii ATCC 27126 on $\mathrm{FeCl}_{3}$ as an iron source. A Iron controls and EDTA treatments. B Colloidal and particulate mineral iron sources, $5 \mu \mathrm{M}$ FeCol $(5 \mathrm{~min})$ : Fe colloids synthesized with 5 min of heating and added at a total iron concentration of $5 \mu \mathrm{M}, 5 \mu \mathrm{M}$ FeCol $(60 \mathrm{~min})$ : Fe colloids synthesized with 60 min of heating and added at a total iron concentration of $5 \mu \mathrm{M}$, $5 \mu \mathrm{M}$ FePart ATD: particulate iron added as Arizona Test Dust at a total iron concentration of $5 \mu \mathrm{M}, 5 \mu \mathrm{M}$ FePart ATD-BL: particulate iron added as Berger-leached Arizona Test Dust at a total iron concentration of $5 \mu \mathrm{M}$. C Biogenic sources of chelated iron each added at a total iron concentration of $5 \mu \mathrm{M}$, DFO desferrioxamine B, Cit citrate, Cyt c cytochrome $c$, Lysate $T$. pseudonana lysate added as the sole iron source. D SRHA treatments, SRHA $500 \mathrm{nM}$ Fe: unmodified SRHA added at a final iron concentration of $500 \mathrm{nM}$, SRHA $30 \mathrm{~min}$ : SRHA extracted for $30 \mathrm{~min}$ with AG50W-X8 cation exchange resin and added at the same volume as unmodified SRHA to final cultures, SRHA Overnight: SRHA extracted overnight with AG50W-X8 cation exchange resin and added at the same volume as unmodified SRHA to final cultures, SRHA 50 nM Fe: unmodified SRHA added at a final iron concentration of $50 \mathrm{nM}$, SRHA $10 \mathrm{nM}$ Fe: unmodified SRHA added at a final iron concentration of $10 \mathrm{nM}$. 
that of the WT strain which remained nearly equal to growth on the $\mathrm{FeCl}_{3}$ control (Fig. 2b). When grown on either ferrihydrite colloids synthesized under $60 \mathrm{~min}$ of heating or ATD, the growth of both strains decreased compared to the $\mathrm{FeCl}_{3}$ control indicating there was a fraction of iron inaccessible to both strains from these iron substrates. However, the maximum specific growth rate and maximum cell density of the $\triangle a s b B:: \mathrm{km}^{\mathrm{r}}$ strain were below those of the WT, with the $\triangle a s b B:: \mathrm{km}^{\mathrm{r}}$ strain reaching only $56 \%$ of the maximum cell density of the WT strain when grown on ATD (Fig. S7b). Similar results were obtained for the Berger-leached ATD, the least labile of all mineral sources tested. While there was an observed decrease in the growth rates for both the $\triangle a s b B:: \mathrm{km}^{r}$ and WT strains on this iron source compared to unmodified ATD, the $\triangle a s b B:: \mathrm{km}^{\mathrm{r}}$ strain again reached only $\sim 60 \%$ of the maximum cell density of the WT strain (Fig. S7b). Together, these results indicate that petrobactin solubilizes a portion of total iron from colloidal and particulate sources for biological uptake.

In additional experiments, EDTA was used as a weak ligand in order to control the amount of free iron $\left(\mathrm{Fe}^{\prime}\right)$ in the solution. The total iron concentration in the media was held constant at $5 \mu \mathrm{M}$, but varying concentrations of EDTA resulted in treatments with $\sim 5$ and $0.5 \mathrm{nM} \mathrm{Fe}^{\prime}$, leaving the majority of iron in the form of a Fe-EDTA complex (Supplemental Materials and Methods). The WT strain was able to maintain maximum specific growth rates under each of these experimental conditions nearly equal to that of growth on the $\mathrm{FeCl}_{3}$ control (Fig. 2a). In contrast, the growth of the $\Delta a s b B:: \mathrm{km}^{\mathrm{r}}$ strain responded strongly to the $\mathrm{Fe}^{\prime}$ concentration, and with less than $1 \mathrm{nM} \mathrm{Fe}^{\prime}$ in solution, the maximum specific growth rate and maximum cell density of the $\triangle a s b B:: \mathrm{km}^{\mathrm{r}}$ strain drastically decreased, falling even below that of the iron deplete control (Figs. 2a, S5a, and S7a). These results indicate that the WT strain was able to access iron bound to EDTA, thereby accessing the total iron in solution via the production of petrobactin, while the $\triangle a s b B:: \mathrm{km}^{\mathrm{r}}$ strain was reliant solely on $\mathrm{Fe}^{\prime}$ as an iron source.

In contrast, when grown on the discrete organic iron-ligand complexes ferrioxamine $B$, ferric citrate, heme, and cytochrome $C$, both the WT and $\triangle a s b B:: \mathrm{km}^{\mathrm{r}}$ strains exhibited similar growth rates and maximum cell densities with growth rates actually exceeding those of growth on $\mathrm{FeCl}_{3}$ (Figs. 2c, S5c, and S7c). In addition, the growth rates of the $\triangle a s b B:: \mathrm{km}^{\mathrm{r}}$ strain were statistically greater than those of the WT when grown on ferrioxamine and ferric citrate complexes. However, both strains reached the same maximum cell densities on these sources indicating that ultimately the same total amount of iron from these sources was accessible to both strains. Based on the preparation of these substrates, the concentrations of $\mathrm{Fe}^{\prime}$ in these experiments are expected to be negligible (Supplemental Materials and Methods). Therefore, growth can be interpreted as the ability to acquire iron from the iron-ligand complex itself and reinforces the ability of Alteromonas spp. to efficiently utilize larger, organic substrates [31].

Growth of the WT and $\triangle a s b B:: \mathrm{km}^{\mathrm{r}}$ strains was also tested on heterogeneous sources of organically complexed iron. This included unfiltered phytoplankton lysate (therefore comprised of heterogenous soluble, colloidal, and particulate organic iron phases) as well as SRHA reference material, consisting of dissolved iron associated with humic acids. The maximum specific growth rate of the $\triangle a s b B:: \mathrm{km}^{r}$ strain on phytoplankton lysate as an iron source was slightly lower compared to that of the WT strain (Fig. 2c), indicating that a fraction of iron was made readily available by siderophore production allowing for more efficient growth. However, maximum cell densities of $\triangle a s b B:: \mathrm{km}^{\mathrm{r}}$ equal to those of the WT strain were achieved (Figs. S5d and S7c) indicating that ultimately a similar magnitude of bioavailable iron was present in the lysate regardless of siderophore production. When grown on SRHA, differences in growth were only observed once the most labile fractions of iron were removed or diluted below replete levels (Supplemental Materials and Methods). In these treatments, the WT reached somewhat higher growth rates and maximum cell densities compared to the $\triangle a s b B:: \mathrm{km}^{\mathrm{r}}$ strain (Figs. 2d, S6a, S6b, and S7d) indicating that a small fraction of iron associated with SRHA seems to be available to the WT strain specifically through the production of petrobactin but that a large fraction is highly bioavailable even in the absence of siderophore production.

\section{Detection of petrobactin in the North Pacific}

The Gradients 1.0 cruise along $158^{\circ} \mathrm{W}$ in the North Pacific sampled across a wide range of biogeochemical conditions moving from the North Pacific Subtropical Gyre into the North Pacific Transition Zone (Figs. 3a and S8). The transition zone chlorophyll front (TZCF; defined as the $0.2 \mathrm{mg} \mathrm{m}^{-3}$ surface chlorophyll contour [63]) was located at $32.5^{\circ} \mathrm{N}$ (Fig. 3a). Surface nitrate $\left(\mathrm{NO}_{3}{ }^{-}\right)$concentrations remained close to detection limits until crossing the TZCF where concentrations significantly increased and surface maximums near $6 \mu \mathrm{M}$ were observed (Fig. S8c) [64]. Dissolved iron concentrations at the surface remained below $0.5 \mathrm{nM}$ across the entire transect, reaching minimum values near $0.06 \mathrm{nM}$ across the TZCF (Fig. S8d). $\mathrm{MS}^{1}$ peaks corresponding to petrobactin $\left(719.361 \mathrm{~m} / \mathrm{z}[\mathrm{M}+\mathrm{H}]^{+}\right.$, $\left.\mathrm{C}_{34} \mathrm{H}_{50} \mathrm{~N}_{6} \mathrm{O}_{11}\right)$ and a putative petrobactin derivative $(691.330 \mathrm{~m} / \mathrm{z}$ $\left.[\mathrm{M}+\mathrm{H}]^{+}, \mathrm{C}_{32} \mathrm{H}_{46} \mathrm{~N}_{6} \mathrm{O}_{11}\right)$ were detected in the extracts of seawater samples collected from this transect following LC-ESI-MS analysis (Fig. 3b, c). Both of these siderophores were detected exclusively in the apo form; however, it is unclear at this point if this is a true environmental phenomenon or a result of sample processing. Petrobactin was detected exclusively in samples collected from below $100 \mathrm{~m}$, primarily between 100 and $200 \mathrm{~m}$ (Fig. 3b). However, beyond the TZCF petrobactin was detected exclusively at $400 \mathrm{~m}$. In contrast, the petrobactin derivative was detected primarily between the surface and $150 \mathrm{~m}$ across the entire transect but was detected as deep as $400 \mathrm{~m}$ in a single sample (Fig. 3c). Petrobactin was detected in samples with a range of dissolved iron from 0.2 to $1.0 \mathrm{nM}$.

\section{Distribution of petrobactin-like biosynthetic pathways in the marine environment}

A search for petrobactin biosynthetic pathways within MAGs assembled from the Tara Oceans dataset [45] detected 66 genomes encoding at least one putative NIS-type siderophore synthase. Of these 66 positive hits, five genomes exhibited the colocalization of genes encoding the NIS-type synthase with a putative 3-dehydroshikimate dehydratase (asbF). Manual inspection confirmed a complete petrobactin-like biosynthetic pathway in each of these five MAGs (Fig. S9). Putative TBDTs and ATPbinding cassette transporters for iron substrates adjacent to these biosynthetic gene clusters further support this annotation. Four of these genomes are classified as belonging to the Marinobacter genus (SP36, IN15, EAC19, and ARS1015) and share $>96 \%$ ANI with each other, indicating they are members of the same species. The fifth MAG is an unclassified Alteromonadaceae (EAC69). A similar search for petrobactin-like biosynthetic pathways in the genomes of cultured bacterial isolates revealed a more diverse distribution of this pathway across Gammaproteobacteria, Alphaproteobacteria, and Bacilli (Supplemental Results, Fig. S10, Dataset S1).

When reads from the entire Tara Oceans metagenomic dataset $[65,66]$ are mapped to the five MAGs with complete petrobactinlike biosynthetic pathways, they are detected in every major ocean basin sampled by the Tara expedition at both the surface and deep chlorophyll maximum (DCM) (Figs. 4, S11, and S12). Due to the high ANI between the four Marinobacter genomes, a combined read count was constructed in order to capture the full breadth of the species-level environmental population across the global ocean (see Materials and Methods for calculation details) (Fig. 4, Dataset S2). At this level of analysis, the highest read counts from the Marinobacter MAGs were detected at the surface in the South Pacific and Arabian Sea (Fig. 4). Read counts attributed to 
the individual Marinobacter MAGs all follow a similar global distribution with variations capturing more specific phylogenetic relationships (approximately equivalent to strains) such that reads associated with ARS1015 were detected in the North Atlantic and the Mediterranean Sea at a greater abundance compared to the other three Marinobacter MAGs (Fig. S11b). At the DCM, distributions of the Marinobacter genomes followed a similar pattern to the surface (Figs. 4 and S12b). Read counts for the Alteromondaceae MAG (EAC69) were generally lower than those of the Marinobacter MAGs by 1-2 orders of magnitude (Figure S11C, S12c). However, in a single sample from the East Africa Coastal region the genome coverage of EAC69 was greater than that of the Marinobacter MAGs. Read counts for EAC69 were found at a similar magnitude in surface samples and at the DCM with the exception of the South Pacific where read counts were up to an order of magnitude greater at the DCM than in corresponding surface samples (Fig. S12c).

\section{DISCUSSION}

It is now recognized that a significant fraction of dissolved iron in the marine environment is complexed by a pool of organic ligands, allowing dissolved iron to accumulate to concentrations above that set by its inorganic solubility [23]. A growing number of measurements of iron-binding ligands in the marine environment in recent years, both through electrochemical techniques and the direct isolation of ligands such as siderophores, reveal a dynamic ligand pool [20-23, 67]. In addition, model studies have concluded that ligand concentrations have a large influence on iron availability and resultant global carbon cycling, even more so than variations in direct iron input [68]. Yet, while organic ligands have emerged as major controls on iron biogeochemical cycling, much remains to be learned regarding their sources, sinks, and definitive roles in the marine environment. As a significant fraction of the total iron-binding ligand pool, understanding the impact of siderophores on iron biogeochemical cycling will be an important

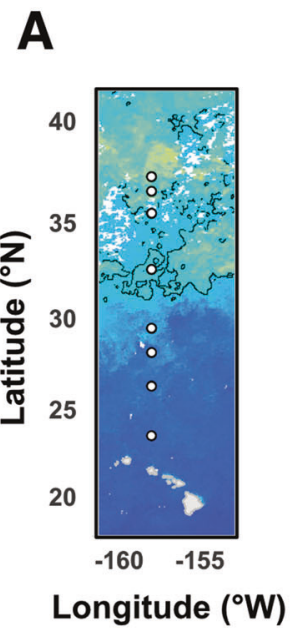

B

Petrobactin Abundance

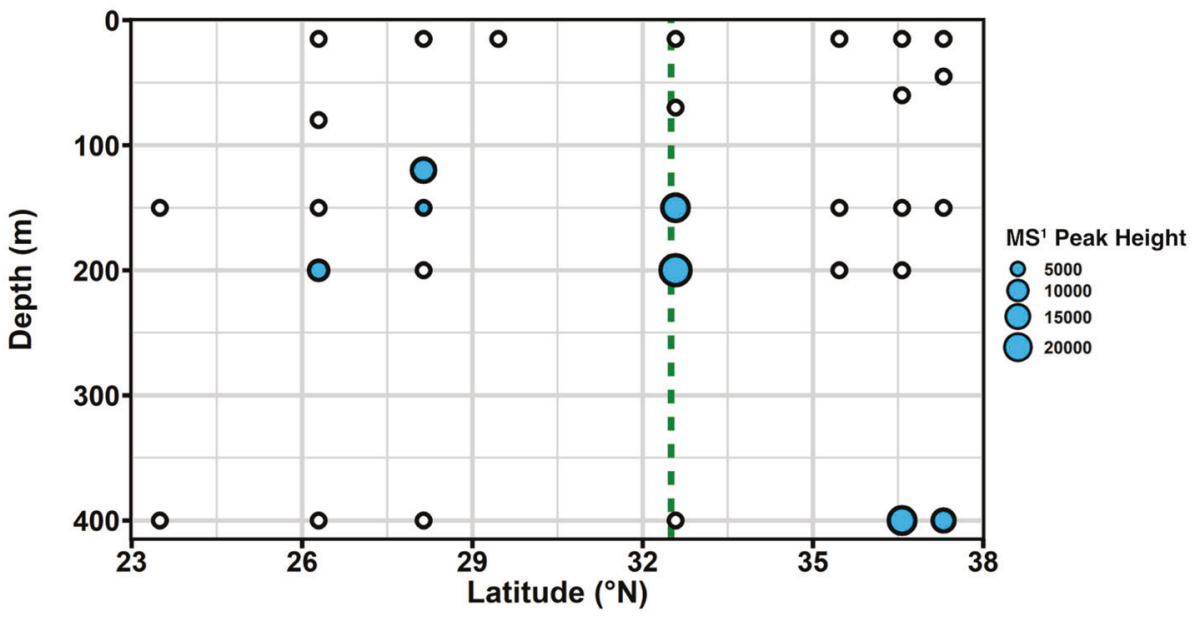

C Petrobactin Derivative Abundance

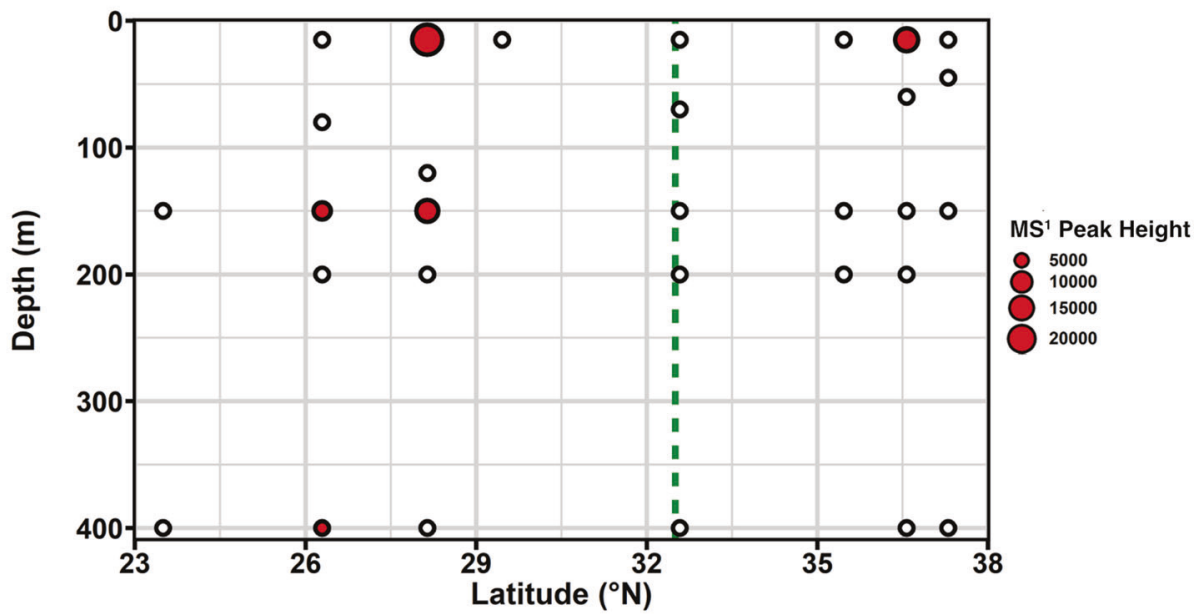

Fig. 3 Distribution of petrobactin across the North Pacific as detected during April 2016. A Station map of siderophore sampling locations along $158^{\circ} \mathrm{W}$ between 23 and $38^{\circ} \mathrm{N}$ collected during the Gradients 1.0 cruise overlain on MODIS sea surface chlorophyll concentrations (mg $\mathrm{m}^{-3}, 4 \mathrm{~km}$ resolution, monthly averages for April 2016). Black lines depict the $0.2 \mathrm{mg} \mathrm{m}^{-3}$ chlorophyll contours. B Distribution of petrobactin $\left(\mathrm{C}_{34} \mathrm{H}_{50} \mathrm{~N}_{6} \mathrm{O}_{11}\right)$ along this transect. Petrobactin was detected in samples depicted with filled blue circles and the size of the circle is proportional to petrobactin abundance as determined by the $\mathrm{MS}^{1}$ peak height. Petrobactin was not detected in samples represented by open circles. The dashed line marks the TZCF. C Distribution of a petrobactin derivative $\left(\mathrm{C}_{32} \mathrm{H}_{46} \mathrm{~N}_{6} \mathrm{O}_{11}\right)$ along this transect. The petrobactin derivative was detected in samples depicted with filled red circles and the size of the circle is proportional to the derivative abundance as determined by MS $^{1}$ peak height. The derivative was not detected in samples represented by open circles. The dashed line marks the TZCF. 
A

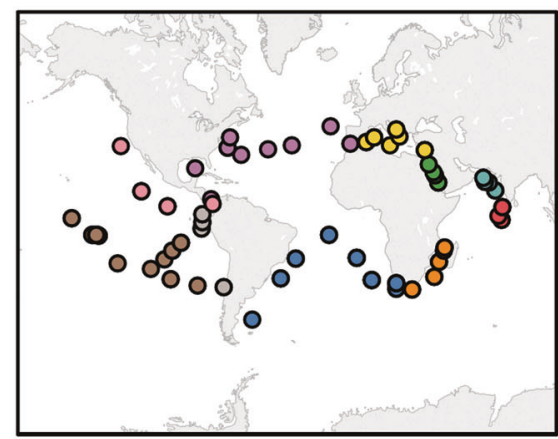

Region

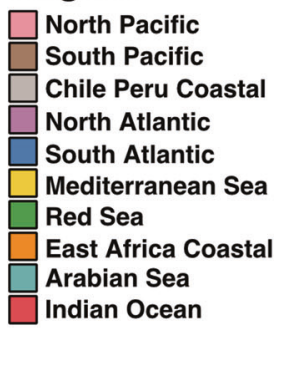

B

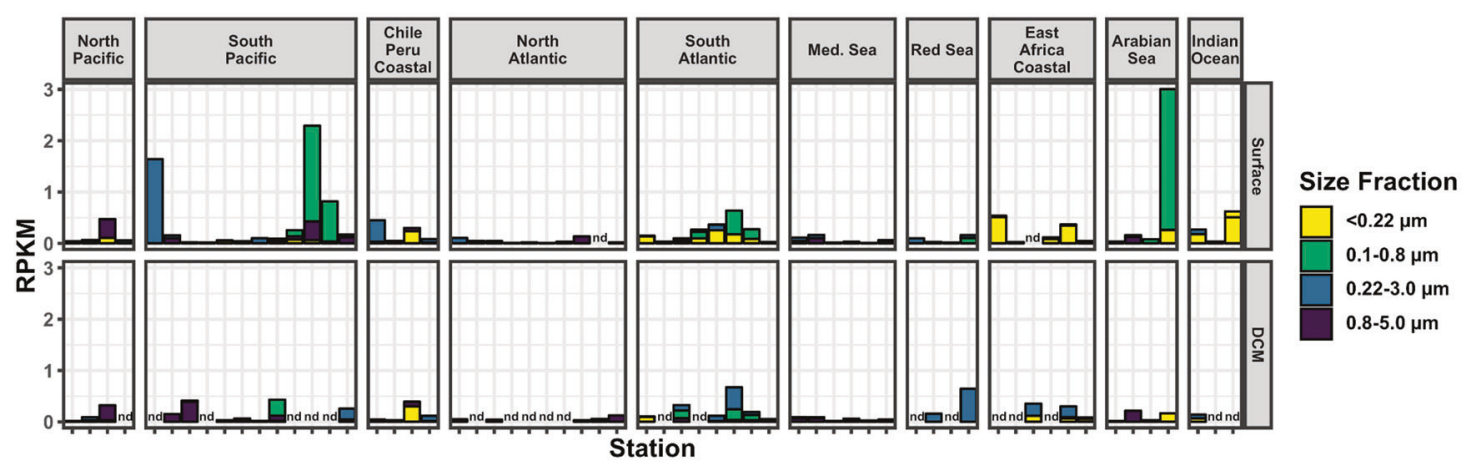

Fig. 4 Distribution of total reads from the Tara Oceans dataset that recruited to four Marinobacter MAGs sharing $>95 \%$ ANI and containing a petrobactin-like biosynthetic gene cluster. A Station map of Tara Oceans sampling locations colored according to region. B Abundance of reads that recruited to the Marinobacter MAGs represented as a species-level environmental population at both the surface (top panel) and DCM (bottom panel) across the Tara Oceans dataset. RPKM values were determined by summing the reads recruited to all four MAGs belonging to the species for a given sample and using an estimated complete species genome length for normalization (see Materials and Methods for complete details). Samples grouped according to the oceanic region as defined in panel A and colored by corresponding sample size fraction. Columns labeled nd indicates that a sample was not collected at that depth for a given station. Raw data for this figure can be found in Dataset S2.

step in this process. We have demonstrated that the production of the siderophore petrobactin by a marine copiotrophic bacterium increases the bioavailability of iron from a number of discrete iron sources. Furthermore, petrobactin has been detected for the first time directly from seawater in the North Pacific, and genomic evidence points to a wide distribution of the petrobactin biosynthetic pathway in the marine environment. As discussed below, these results shed light on the role of siderophore production for iron acquisition by marine microbes and the resultant implications of siderophore biosynthesis for iron biogeochemical cycling.

\section{A significant role for siderophore production in the incorporation of new iron into the marine environment}

The major sources of new iron to the marine environment include atmospheric dust, hydrothermal vents, and the resuspension of sediments along continental margins [67]. Iron from these sources largely consists of colloidal and particulate mineral phases that are characterized by low solubility in oxygenated seawater. Given the tendency of these particles to sink and be scavenged from the water column, it is unclear how much iron from these particulate sources ultimately contributes to the dissolved and bioavailable pools of iron in the marine environment. The role of siderophore production in the acquisition of iron from these mineral sources has long been hypothesized. In particular, the relatively recent recognition that hydrothermal input contributes a significant fraction of new iron to the marine environment $[69,70]$ has been largely attributed to the organic complexation [71-73] and microbial acquisition [74] of iron from this source. While dissolution and modeling studies support these conclusions [24$29,75]$, up to this point, there has been a lack of experimental evidence demonstrating that siderophore-based acquisition of iron from mineral sources supports bacterial growth in the marine environment. Through the generation of a knockout mutant and the use of a controlled biological system, we have shown that petrobactin production by a marine bacterium liberates a fraction of iron from colloidal and particulate mineral iron sources for biological use (Figs. 2b and S7b). An outstanding research question is whether this behavior is shared with other siderophores [76], but these results further suggest that siderophore production is a significant mechanism by which iron from external, particulate inputs can be incorporated into soluble and bioavailable pools of iron (Fig. 5). While directly benefitting the siderophore-producing bacterium, the solubilization of iron from particulates by siderophores also has the potential to confer benefits to non-siderophore producing microbes that can access iron from iron-siderophore complexes but otherwise would be unable to directly utilize iron from lithogenic sources [77]. Furthermore, the siderophore-driven dissolution of iron from particles and the subsequent acquisition of these iron-siderophore complexes by marine microbes transitions this mineral-phase iron to a new pool contained within biomass where its speciation is further transformed and where it may be retained for biological use on longer timescales via recycling [78]. This confirms an important role for biologically produced iron-binding ligands in controlling the balance between the scavenging and retention of dissolved iron in the marine environment [79-82]. These results place further emphasis on the need to understand factors 


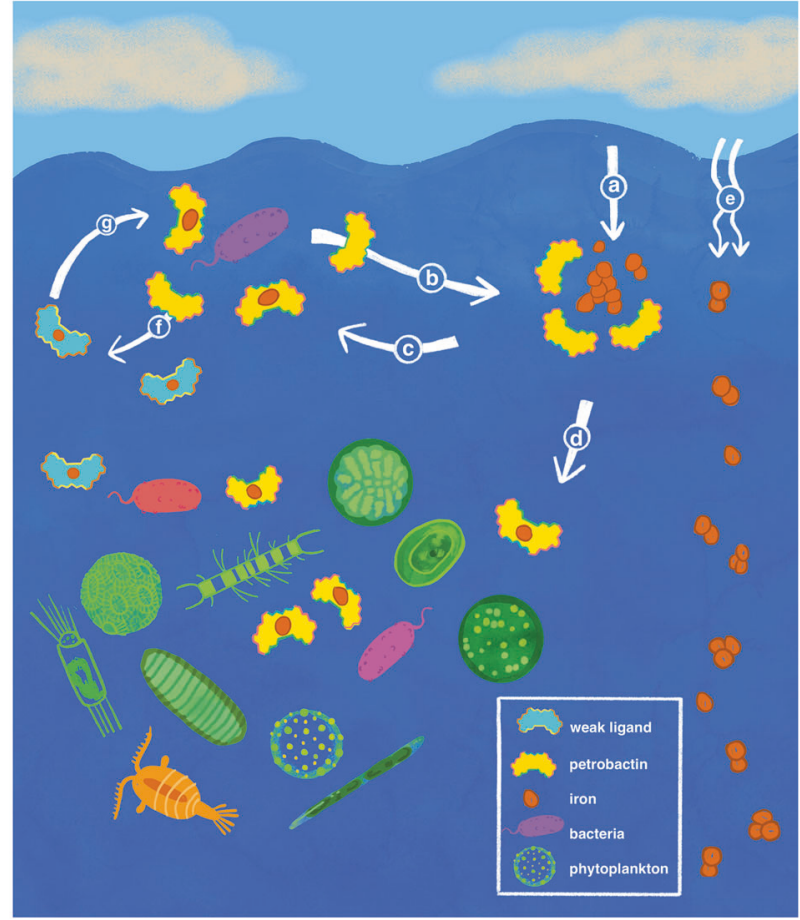

Fig. 5 Proposed role of petrobactin production on the bioavailability of iron in the marine environment. a Iron in the form of lithogenic particles is delivered to the surface ocean via atmospheric dust. b Petrobactin is produced and released into the marine environment by $A$. macleodii and additional petrobactin-producing marine bacteria. c Petrobactin binds iron from lithogenic particles transferring this iron to the dissolved iron pool where it can be acquired by the producing bacterium. d The dissolved ironpetrobactin complex is also now available to the greater microbial community where this iron may be acquired via one of several potential mechanisms such as the direct acquisition of the complex, reductive dissociation as $\mathrm{Fe}(\mathrm{II})$, or exchange with another strong ligand followed by subsequent transport. e In the absence of petrobactin, iron remains within the lithogenic particulate pool and sinks out of the surface ocean in a largely non-bioavailable form. f Petrobactin also interacts with iron bound to weaker organic ligands in the marine environment. g Petrobactin acquires iron from weaker ligands via ligand exchange converting it to a form readily taken up by $A$. macleodii and other microbes with appropriate transport mechanisms. Illustration credit: Rachael Chan, The Art Center College of Design.

influencing siderophore production, degradation, and distribution as these are likely some of the major driving forces controlling the amount of new iron effectively incorporated into the marine environment and available for biological use.

\section{Petrobactin production can effectively sequester iron from weak to intermediate iron-ligand complexes}

In the results presented here, the most pronounced growth advantage observed in the WT due to siderophore production was growth on EDTA-bound iron (Figs. 2a and S7a). This demonstrates that siderophore production can increase the bioavailability of iron from exogenous iron-ligand compounds, particularly when a direct transport mechanism for the complex is absent, as would be the case for the synthetic ligand EDTA. With a relatively weak binding strength for iron in seawater [83], EDTA serves as a model for the weakest class of iron-binding ligands found in the marine environment [23]. With conditional stability constant with respect to $\mathrm{Fe}^{\prime}$ of $10^{11.4}$ [84], petrobactin would be expected to effectively sequester iron from EDTA, allowing the WT to access the total amount of iron in solution. In contrast, without petrobactin, the $\triangle a s b B:: \mathrm{km}^{r}$ strain is dependent solely on $\mathrm{Fe}^{\prime}$ as an iron source in these treatments. Likewise, SRHA is a well-characterized reference material consisting of humic acids of terrestrial origin and has been characterized to have an intermediate binding strength to iron in seawater [85]. Particularly in coastal and estuarine environments, humic-like substances can play an important role in iron biogeochemistry $[22,85-89]$. In these environments, it has been observed that iron-binding humics could account for the entire iron-ligand pool [85] and up to 5\% of the total dissolved organic carbon pool [90]. Currently, there is no known cellular transporter that would allow marine bacteria to directly access these iron-ligand complexes, yet there appears to be a large fraction of labile iron within SRHA. However, when the most labile fractions were removed or diluted below replete levels, a growth advantage was conferred to the WT strain with the production of petrobactin (Figs. $2 \mathrm{~d}$ and $\mathrm{S7d}$ ). This implies that a portion of iron complexed by humic-like substances in the marine environment is accessible explicitly via exchange with a strong ligand as has been previously suggested [87]. In addition to humic-like substances, additional classes of weaker iron-binding ligands that are not structurally well-defined but are widely distributed across the global ocean include compounds excreted by cells, such as exopolymeric substances and saccharides, as well as biological degradation products [91]. It is likely that petrobactin, along with other siderophores, also plays a role in obtaining iron from this non-specific yet abundant pool of ligands (Fig. 5).

In contrast, the $\triangle a s b B:: \mathrm{km}^{r}$ strain was able to maintain maximum growth rates equivalent to those of the WT when tested on various discrete, strong, biogenic iron-ligand complexes (Figs. 2c and S7c). In addition, both of these strains grew at significantly faster rates on these organic sources compared to the $\mathrm{FeCl}_{3}$ control. These results likely reflect the high transport capacity for exogenous iron-ligand complexes found within the ATCC 27126 genome. Unlike the synthetic ligand EDTA, ironligand complexes common to the marine environment can be acquired directly by Gram-negative bacteria via TBDTs. Previous work with this strain identified putative TBDTs for the acquisition of at least 11 different iron-ligand complexes, five of which are thought to be for the acquisition of exogenous siderophores [31]. The results presented here demonstrate that ATCC 27126 does indeed acquire organically complexed iron extremely efficiently. It is also interesting to note the ability of both strains to grow on cytochrome $c$ as an iron source. Cytochrome $c$ is presumed to be too large to cross the bacterial cell membrane in its entirety. In addition, the heme cofactor is covalently bound to the protein, rendering it unavailable via transport through a TBDT without further processing [40]. This suggests that either the heme molecule or the iron atom within cytochrome $c$ is extracted extracellularly, requiring additional cellular machinery beyond a TBDT. However, petrobactin does not appear to play a critical role in this process. All else being equal, these results indicate that no advantage from petrobactin production is conferred in the acquisition of iron from discrete iron-ligand complexes when a corresponding transport mechanism is present. In fact, given that the $\triangle a s b B:: \mathrm{km}^{\mathrm{r}}$ strain could actually maintain faster growth rates on several of these organic complexes, it is possible that the investment in petrobactin production by ATCC 27126 may actually hinder growth in the presence of an iron source that can be directly taken up by the cell. Recent work with the marine copiotroph Vibrio cyclitrophicus $1 \mathrm{~F}-53$ has suggested that siderophore production can be regulated by the presence of an exogenous, bioavailable siderophore [92].

The high transport capacity of ATCC 27126 for biogenic ironligand compounds may also explain the similar growth observed between the WT and $\triangle a s b B:: \mathrm{km}^{\mathrm{r}}$ strains on phytoplankton lysate as an iron source (Figs. 2c and S7c). Cellular transporters for biogenic iron substrates such as heme or iron-containing proteins 
found within the lysate would allow the mutant strain to acquire sufficient iron in order to keep pace with the WT. This highlights the significant role that cellular transporters, in particular, may serve in the uptake of remineralized iron sources from phytoplankton biomass. However, for siderophore-producing marine bacteria with fewer available transporters, siderophore production may be a relatively more important strategy for acquiring biogenic iron. Alternatively, siderophore production may impart a competitive advantage in a mixed community by sequestering iron in a more selective form. The production of strong ligands presumed to be siderophores has been detected at the peak of a stimulated bloom [37], and direct measurements of ferrioxamine siderophores have been made during the degradation of sinking particles $[20,93]$ suggesting that siderophore production does indeed play a role in iron remineralization processes in a natural community. The detection of five TBDTs for exogenous siderophores in the genome of $A$. macleodii ATCC 27126 [31] also suggests the production of multiple types of siderophores within a microbial community is common in environments enriched in organic matter, making siderophore piracy an advantageous strategy for iron acquisition under these conditions [94]. Further work characterizing these dynamics is merited.

\section{The production of petrobactin, a photochemically reactive siderophore, is widespread in the marine environment}

To date, siderophores isolated directly from seawater have fallen within two structural classes-either ferrioxamine-or amphibactin-type siderophores [19-22]. Ferrioxamines are hydrophilic siderophores with hydroxamate chelating groups, whereas amphibactins are characterized by a chelating polar head group bound to a fatty acid tail [15]. In contrast, petrobactin is characterized by two catecholate chelating groups joined via a citrate backbone (Fig. 1). The detection of this third structural class of siderophores across the North Pacific expands our understanding of the cycling of different classes of siderophores in the marine environment and narrows the gap between the wealth of siderophores isolated in culture and the relatively few structures detected directly in the marine environment thus far. In addition, the a-hydroxycarboxylic acid moiety in the citrate backbone of petrobactin means it is subject to photochemical decarboxylation when bound to $\mathrm{Fe}$ (III) [58]. Photolysis of an iron-siderophore complex results in the reduction of $\mathrm{Fe}$ (III) to $\mathrm{Fe}$ (II) and an initial loss of complexation. This change in iron speciation will inherently affect iron availability and is thought to be a significant factor in iron biogeochemical cycling within the marine environment [95]. While photochemical degradation is generally considered a loss term for strong iron-binding ligands [96], in the case of petrobactin, decarboxylation leaves much of the original structure intact, including the chelating catecholate groups, resulting in an almost unchanged binding affinity for iron [84]. The petrobactin photoproduct, therefore, represents another significant ironbinding ligand pool that may be present in the marine environment, although it was not specifically searched for in this dataset. The detection of a photoreactive siderophore directly from seawater is a significant step in understanding the cycling of this class of siderophores in the natural marine environment which has the potential to act as a unique control on iron availability [95].

While the proposed petrobactin derivative detected in this study has not been isolated from a marine bacterium to date, the biosynthesis of this derivative has been demonstrated in vitro via the petrobactin biosynthetic pathway of $B$. anthracis utilizing the starting substrate norspermidine in place of spermidine, which links the catecholate moiety to the citrate backbone of petrobactin [97]. Both norspermidine and spermidine are polyamines known to be synthesized by a range of marine microbes but with notable taxonomic differences in the prevalence of these biosynthetic capabilities [98-100]. Within Gammaproteobacteria, spermidine is commonly synthesized across multiple orders while norspermidine is primarily produced by members of the order Vibrionales [99]. Based on these taxonomic differences, the distribution of these two petrobactin structures across the North Pacific may be reflective of the ability of the corresponding microbial communities to synthesize or obtain the respective starting substrates. Alternatively, it is possible that differences in the photochemical activity of these two compounds could account for differences in their distribution. As discussed above, the photochemical activity of petrobactin is well characterized, and loss due to photodegradation could explain the absence of petrobactin in the top $100 \mathrm{~m}$ of the North Pacific. While the petrobactin derivative would also be expected to be subject to photochemical loss due to the presence of a citrate backbone, this has not been experimentally determined. The presence of the derivative in sunlit waters of the North Pacific may suggest different photochemical dynamics between these two compounds. Additional work will be needed to determine whether differences in microbial communities, photochemical activity, or some combination of the two are responsible for controlling the distribution of these two siderophores in the marine environment.

Beyond the direct detection of petrobactin in the North Pacific, our examination of available genomic data, from both MAGs and cultivated strains, indicates that the potential for petrobactin biosynthesis is concentrated within the classes Alphaproteobacteria, Gammaproteobacteria, and Bacilli (Figs. S9 and S10) but is geographically widespread in the marine environment (Figs. 4, S11, and S12). On their own, cultured members of Alteromonas possessing a petrobactin, biosynthetic gene cluster are some of the most prevalent species in the Tara Oceans dataset [32]. Our results substantiate earlier findings, based on the detection of $a s b E$ homologs via $\mathrm{qPCR}$, which suggested that up to $2 \%$ of total prokaryotic cells in the North Atlantic may possess a petrobactinlike biosynthetic pathway [101]. The wide geographic distribution of species with the capacity to produce petrobactin or petrobactin-like derivatives implies it is playing a significant role in iron acquisition and cycling across the marine environment and renders the results presented here as ecologically significant. As is the case for many characterized siderophore-producing marine bacteria, these confirmed or putative petrobactin-producing strains are largely copiotrophic species that can quickly become dominant members of the community and exert a significant influence on biogeochemical cycling. The ability to access an otherwise non-bioavailable pool of iron, particularly that from colloidal and particulate sources, via the production of petrobactin may be an important factor in this copiotrophic lifestyle.

\section{CONCLUSION}

In summary, we have utilized A. macleodii ATCC 27126 as an effective model organism in order to demonstrate experimentally that the acquisition of iron from specific sources in the marine environment is facilitated by the production of a siderophore, in this case, petrobactin. In particular, the bioavailability of colloidal and particulate mineral iron and iron associated with weaker ligand pools was increased through the production of petrobactin. This demonstrates the significant role that heterotrophic bacteria play in the incorporation of new iron into the marine environment via siderophore production (Fig. 5). We also report the first detection of petrobactin, a photochemically reactive siderophore, directly from seawater and have found, based on genomic evidence, that the capacity for petrobactin production is widespread throughout the marine environment. Together these results advance our mechanistic understanding of the role of siderophore production in the marine environment providing an improved framework for understanding iron biogeochemical cycling wherein iron speciation, bioavailability, and residence time can be directly influenced by microbial activity. 


\section{REFERENCES}

1. Boyd PW, Ellwood MJ. The biogeochemical cycle of iron in the ocean. Nat Geosci. 2010;3:675-82.

2. Boyd PW, Jickells T, Law CS, Blain S, Boyle EA, Buesseler KO, et al. Mesoscale iron enrichment experiments 1993-2005: Synthesis and future directions. Science 2007;315:612-7.

3. Tortell PD, Maldonado MT, Price NM. The role of heterotrophic bacteria in ironlimited ocean ecosystems. Nature 1996;383:330-2.

4. Maldonado MT, Price NM. Utilization of iron bound to strong organic ligands by plankton communities in the subarctic Pacific Ocean. Deep Res Part II Top Stud Oceanogr. 1999;46:2447-73.

5. Fourquez $M$, Devez A, Schaumann A, Guéneuguès $A$, Jouenne $T$, Obernosterer I, et al. Effects of iron limitation on growth and carbon metabolism in oceanic and coastal heterotrophic bacteria. Limnol Oceanogr. 2014;59:349-60.

6. Hopkinson BM, Barbeau KA. Iron transporters in marine prokaryotic genomes and metagenomes. Environ Microbiol. 2012;14:114-28.

7. Reid RT, Livet DH, Faulkner DJ, Butler A. A siderophore from a marine bacterium with an exceptional ferric ion affinity constant. Nature 1993;366:455-8.

8. Trick CG. Hydroxamate-siderophore production and utilization by marine eubacteria. Curr Microbiol. 1989;18:375-8.

9. Haygood MG, Holt PD, Butler A. Aerobactin production by a planktonic marine Vibrio sp. Limnol Oceanogr. 1993;38:1091-7.

10. Granger J, Price NM. The importance of siderophores in iron nutrition of heterotrophic marine bacteria. Limnol Oceanogr. 1999;44:541-55.

11. Wilhelm SW, Trick CG. Iron-limited growth of cyanobacteria: multiple siderophore production is a common response. Limnol Oceanogr. 1994;39:1979-84.

12. Winkelmann G, Schmid DG, Nicholson G, Jung G, Colquhoun DJ. Bisucaberin-a dihydroxamate siderophore isolated from Vibrio salmonicida, an important pathogen of farmed Atlantic salmon (Salmo salar). BioMetals 2002;15:153-60.

13. Reid RT, Butler A. Investigation of the mechanism of iron acquisition by the marine bacterium Alteromonas luteoviolaceus: characterization of siderophore production. Limnol Oceanogr. 1991;36:1783-92.

14. Butler A. Acquisition and utilization of transition metal ions by marine organisms. Science 1998;281:207-10.

15. Vraspir JM, Butler A. Chemistry of marine ligands and siderophores. Ann Rev Mar Sci. 2009;1:43-63.

16. Maldonado MT, Price NM. Reduction and transport of organically bound iron by Thalassiosira oceanica (Bacillariophyceae). J Phycol. 2001;37:298-310.

17. Kazamia E, Sutak R, Paz-Yepes J, Dorrell RG, Vieira FRJ, Mach J, et al. Endocytosismediated siderophore uptake as a strategy for Fe acquisition in diatoms. Sci Adv. 2018;4:eaar4536.

18. Coale TH, Moosburner M, Oborník M, Barbeau KA, Allen AE. Reductiondependent siderophore assimilation in a model pennate diatom. Proc Natl Acad Sci USA. 2019;116:23609-17.

19. Mawji E, Gledhill M, Milton JA, Zubkov MV, Thompson A, Wolff GA, et al. Production of siderophore type chelates in Atlantic Ocean waters enriched with different carbon and nitrogen sources. Mar Chem. 2011;124:90-9.

20. Bundy RM, Boiteau RM, McLean C, Turk-Kubo KA, Mcllvin MR, Saito MA, et al. Distinct siderophores contribute to iron cycling in the mesopelagic at station ALOHA. Front Mar Sci 2018;5:61.

21. Boiteau RM, Mende DR, Hawco NJ, Mcllvin MR, Fitzsimmons JN, Saito MA, et al. Siderophore-based microbial adaptations to iron scarcity across the eastern Pacific Ocean. Proc Natl Acad Sci USA 2016;113:14237-42.

22. Boiteau RM, Till CP, Coale TH, Fitzsimmons JN, Bruland KW, Repeta DJ. Patterns of iron and siderophore distributions across the California Current System. Limnol Oceanogr. 2019;64:376-89.

23. Gledhill M, Buck KN. The organic complexation of iron in the marine environment: a review. Front Microbiol. 2012;3:1-17. (FEB)

24. Yoshida T, Hayashi Kl, Ohmoto $\mathrm{H}$. Dissolution of iron hydroxides by marine bacterial siderophore. Chem Geol. 2002;184:1-9.

25. Cocozza C, Tsao CCG, Cheah S-F, Kraemer SM, Raymond KN, Miano TM, et al. Temperature dependence of goethite dissolution promoted by trihydroxamate siderophores. Geochim Cosmochim Acta. 2002;66:431-8.

26. Kraemer SM. Iron oxide dissolution and solubility in the presence of siderophores. Aquat Sci. 2004;66:3-18.

27. Borer PM, Sulzberger B, Reichard P, Kraemer SM. Effect of siderophores on the light-induced dissolution of colloidal iron(III) (hydr)oxides. Mar Chem. 2005;93:179-93.

28. Rosario Lorenzo M, Segovia M, Cullen JT, Maldonado MT. Particulate trace metal dynamics in response to increased $\mathrm{CO} 2$ and iron availability in a coastal mesocosm experiment. Biogeosciences 2020;17:757-70.

29. Kessler N, Kraemer SM, Shaked Y, Schenkeveld WDC. Investigation of siderophore-promoted and reductive dissolution of dust in marine microenvironments such as trichodesmium colonies. Front Mar Sci. 2020;7:45.
30. Koch H, Germscheid N, Freese HM, Noriega-Ortega B, Lücking D, Berger M, et al. Genomic, metabolic and phenotypic variability shapes ecological differentiation and intraspecies interactions of Alteromonas macleodii. Sci Rep. 2020;10:1-14.

31. Manck LE, Espinoza JL, Dupont CL, Barbeau KA. Transcriptomic study of substrate-specific transport mechanisms for iron and carbon in the marine copiotroph Alteromonas macleodii. mSystems 2020;5:e00070-20.

32. Nayfach S, Rodriguez-Mueller B, Garud N, Pollard KS. An integrated metagenomics pipeline for strain profiling reveals novel patterns of bacterial transmission and biogeography. Genome Res. 2016;26:1612-25.

33. Mou X, Sun S, Edwards RA, Hodson RE, Moran MA. Bacterial carbon processing by generalist species in the coastal ocean. Nature 2008;451:708-11.

34. McCarren J, Becker JW, Repeta DJ, Shi Y, Young CR, Malmstrom RR, et al. Microbial community transcriptomes reveal microbes and metabolic pathways associated with dissolved organic matter turnover in the sea. Proc Natl Acad Sci USA. 2010;107:16420-7.

35. López-Pérez M, Gonzaga A, Martin-Cuadrado AB, Onyshchenko O, Ghavidel A Ghai $\mathrm{R}$, et al. Genomes of surface isolates of Alteromonas macleodii: the life of a widespread marine opportunistic copiotroph. Sci Rep. 2012;2:1-11.

36. Shi Y, McCarren J, Delong EF. Transcriptional responses of surface water marine microbial assemblages to deep-sea water amendment. Environ Microbiol. 2012;14:191-206.

37. Hogle SL, Bundy RM, Blanton JM, Allen EE, Barbeau KA. Copiotrophic marine bacteria are associated with strong iron-binding ligand production during phytoplankton blooms. Limnol Oceanogr Lett. 2016;1:36-43.

38. Debeljak P, Toulza E, Beier S, Blain S, Obernosterer I. Microbial iron metabolism as revealed by gene expression profiles in contrasted Southern Ocean regimes. Environ Microbiol. 2019;21:2360-74.

39. Pedler BE, Aluwihare LI, Azam F. Single bacterial strain capable of significant contribution to carbon cycling in the surface ocean. Proc Natl Acad Sci USA. 2014;111:7202-7.

40. Hogle SL, Brahamsha B, Barbeau KA. Direct heme uptake by phytoplanktonassociated roseobacter bacteria. mSystems 2017;2:e00124-16.

41. Diner RE, Schwenck SM, McCrow JP, Zheng H, Allen AE. Genetic manipulation of competition for nitrate between heterotrophic bacteria and diatoms. Front Microbiol. 2016;7:880.

42. Gibson DG, Young L, Chuang RY, Venter JC, Hutchison CA, Smith HO. Enzymatic assembly of DNA molecules up to several hundred kilobases. Nat Methods. 2009;6:343-5.

43. Schwyn B, Neilands JB. Universal chemical assay for the detection and determination of siderophores. Anal Biochem. 1987;160:47-56.

44. Estimation of Growth Rates with Package growthrates [Internet]. https://cran.rproject.org/web/packages/growthrates/vignettes/Introduction.html. cited 2020 May 3.

45. Tully BJ, Graham ED, Heidelberg JF. The reconstruction of 2,631 draft metagenome-assembled genomes from the global oceans. Sci Data. 2018;5:1-8.

46. Pfleger BF, Lee JY, Somu RV, Aldrich CC, Hanna PC, Sherman DH. Characterization and analysis of early enzymes for petrobactin biosynthesis in Bacillus anthracis. Biochemistry 2007;46:4147-57.

47. Lee JY, Janes BK, Passalacqua KD, Pfleger BF, Bergman NH, Liu H, et al. Biosynthetic analysis of the petrobactin siderophore pathway from Bacillus anthracis. J Bacteriol. 2007;189:1698-710.

48. Fox DT, Hotta K, Kim CY, Koppisch AT. The missing link in petrobactin biosynthesis: asbF encodes a (-)-3-dehydroshikimate dehydratase. Biochemistry 2008;47:12251-3.

49. Baars O, Morel FMM, Zhang X. The purple non-sulfur bacterium Rhodopseudomonas palustris produces novel petrobactin-related siderophores under aerobic and anaerobic conditions. Environ Microbiol. 2018;20:1667-76.

50. Hyatt D, Chen GL, LoCascio PF, Land ML, Larimer FW, Hauser LJ. Prodigal: prokaryotic gene recognition and translation initiation site identification. BMC Bioinform. 2010;11:119.

51. Eddy SR. Accelerated profile HMM searches. PLoS Comput. Biol. 2011;7: e1002195.

52. Langmead B, Salzberg SL. Fast gapped-read alignment with Bowtie 2. Nat Methods. 2012;9:357-9.

53. Liao Y, Smyth GK, Shi W. Sequence analysis featureCounts: an efficient general purpose program for assigning sequence reads to genomic features. Bioinformatics 2014;30:923-30.

54. Graham ED, Heidelberg JF, Tully BJ. Binsanity: unsupervised clustering of environmental microbial assemblies using coverage and affinity propagation. PeerJ 2017;2017:e3035.

55. Jain C, Rodriguez-R LM, Phillippy AM, Konstantinidis KT, Aluru S. High throughput $\mathrm{ANI}$ analysis of $90 \mathrm{~K}$ prokaryotic genomes reveals clear species boundaries. Nat Commun. 2018;9:1-8. 
56. Parks DH, Imelfort $M$, Skennerton $C T$, Hugenholtz P, Tyson GW. CheckM: assessing the quality of microbial genomes recovered from isolates, single cells, and metagenomes. Genome Res. 2015;25:1043-55.

57. Baars O, Morel FMM, Perlman DH. ChelomEx: isotope-assisted discovery of metal chelates in complex media using high-resolution LC-MS. Anal Chem. 2014;86:11298-305.

58. Barbeau K, Zhang G, Live DH, Butler A. Petrobactin, a photoreactive siderophore produced by the oil-degrading marine bacterium Marinobacter hydrocarbonoclasticus. J Am Chem Soc. 2002;124:378-9.

59. Wells ML, Zorkin NG, Lewis AG. The role of colloid chemistry in providing a source of iron to phytoplankton. J Mar Res. 1983;41:731-46.

60. Cwiertny DM, Baltrusaitis J, Hunter GJ, Laskin A, Scherer MM, Grassian VH. Characterization and acid-mobilization study of iron-containing mineral dust source materials. J Geophys Res Atmos. 2008;113:D05202.

61. Perron MMG, Strzelec M, Gault-Ringold M, Proemse BC, Boyd PW, Bowie AR. Assessment of leaching protocols to determine the solubility of trace metals in aerosols. Talanta 2020;208:120377.

62. Berger CJM, Lippiatt SM, Lawrence MG, Bruland KW. Application of a chemical leach technique for estimating labile particulate aluminum, iron, and manganese in the Columbia River plume and coastal waters off Oregon and Washington. J Geophys Res. 2008;113:C00B01.

63. Polovina JJ, Howell E, Kobayashi DR, Seki MP. The transition zone chlorophyll front, a dynamic global feature defining migration and forage habitat for marine resources. Prog Oceanogr. 2001;49:469-83.

64. Gradoville MR, Farnelid H, White AE, Turk-Kubo KA, Stewart B, Ribalet F, et al. Latitudinal constraints on the abundance and activity of the cyanobacterium UCYN-A and other marine diazotrophs in the North Pacific. Limnol Oceanogr. 2020;65:1858-75.

65. Sunagawa S, Coelho LP, Chaffron S, Kultima JR, Labadie K, Salazar G, et al. Structure and function of the global ocean microbiome. Science 2015;348:1261359.

66. Pesant S, Not F, Picheral M, Kandels-Lewis S, Le Bescot N, Gorsky G, et al. Open science resources for the discovery and analysis of Tara Oceans data. Sci Data. 2015;2:1-16.

67. Tagliabue A, Bowie A, Boyd P, Buck KN, Johnson KS, Saito M. The integral role of iron in ocean biogeochemistry. Nature 2017;543:51-9.

68. Tagliabue A, Aumont O, Bopp L. The impact of different external sources of iron on the global carbon cycle. Geophys Res Lett. 2014;41:920-6.

69. Fitzsimmons JN, Boyle EA, Jenkins WJ. Distal transport of dissolved hydrothermal iron in the deep South Pacific Ocean. Proc Natl Acad Sci USA. 2014;111:16654-61.

70. Resing JA, Sedwick PN, German CR, Jenkins WJ, Moffett JW, Sohst BM, et al. Basin-scale transport of hydrothermal dissolved metals across the South Pacific Ocean. Nature 2015;523:200-3.

71. Bennett SA, Achterberg EP, Connelly DP, Statham PJ, Fones GR, German CR. The distribution and stabilisation of dissolved Fe in deep-sea hydrothermal plumes. Earth Planet Sci Lett. 2008;270:157-67.

72. Sander SG, Koschinsky A. Metal flux from hydrothermal vents increased by organic complexation. Nat Geosci. 2011;4:145-50.

73. Fitzsimmons JN, John SG, Marsay CM, Hooman CL, Nicholas SL, Toner BM, et al. Iron persistence in a distal hydrothermal plume supported by dissolvedparticulate exchange. Nat Geosci. 2017;10:195-201.

74. Li M, Toner BM, Baker BJ, Breier JA, Sheik CS, Dick GJ. Microbial iron uptake as a mechanism for dispersing iron from deep-sea hydrothermal vents. Nat Commun. 2014;5:1-8

75. Leventhal GE, SchiessI KT, Ackermann M. Why microbes secrete molecules to modify their environment: the case of iron-chelating siderophores. J R Soc Interface. 2019;16:20180674.

76. Ferret C, Sterckeman T, Cornu JY, Gangloff S, Schalk IJ, Geoffroy VA. Siderophore-promoted dissolution of smectite by fluorescent Pseudomonas. Environ Microbiol Rep. 2014;6:459-67.

77. Basu S, Gledhill M, de Beer D, Prabhu Matondkar SG, Shaked Y. Colonies of marine cyanobacteria Trichodesmium interact with associated bacteria to acquire iron from dust. Commun Biol. 2019;2:1-8.

78. Boyd PW, Ellwood MJ, Tagliabue A, Twining BS. Biotic and abiotic retention, recycling and remineralization of metals in the ocean. Nat Geosci. 2017;10:167-73.

79. Kuma K, Nishioka J, Matsunaga K. Controls on iron(III) hydroxide solubility in seawater: the influence of $\mathrm{pH}$ and natural organic chelators. Limnol Oceanogr. 1996;41:396-407.

80. Chen M, Wang WX, Guo L. Phase partitioning and solubility of iron in natural seawater controlled by dissolved organic matter. Glob Biogeochem Cycles. 2004;18:1-12.

81. Tagliabue A, Bowie AR, DeVries T, Ellwood MJ, Landing WM, Milne A, et al. The interplay between regeneration and scavenging fluxes drives ocean iron cycling. Nat Commun. 2019;10:4960.
82. Lauderdale JM, Braakman R, Forget G, Dutkiewicz S, Follows MJ. Microbial feedbacks optimize ocean iron availability. Proc Natl Acad Sci USA. 2020;117:4842-9.

83. Hudson RJM, Covault DT, Morel FMM. Investigations of iron coordination and redox reactions in seawater using 59Fe radiometry and ion-pair solvent extraction of amphiphilic iron complexes. Mar Chem. 1992;38:209-35.

84. Barbeau K, Rue EL, Trick CG, Bruland KW, Butler A. Photochemical reactivity of siderophores produced by marine heterotrophic bacteria and cyanobacteria based on characteristic Fe(III) binding groups. Limnol Oceanogr. 2003;48:1069-78.

85. Laglera LM, van den Berg CMGG. Evidence for geochemical control of iron by humic substances in seawater. Limnol Oceanogr. 2009;54:610-9.

86. Bundy RM, Biller DV, Buck KN, Bruland KW, Barbeau KA. Distinct pools of dissolved iron-binding ligands in the surface and benthic boundary layer of the California Current. Limnol Oceanogr. 2014;59:769-87.

87. Batchelli S, Muller FLL, Chang KC, Lee CL. Evidence for strong but dynamic ironhumic colloidal associations in humic-rich coastal waters. Environ Sci Technol. 2010;44:8485-90.

88. Stolpe B, Guo L, Shiller AM, Hassellöv M. Size and composition of colloidal organic matter and trace elements in the Mississippi River, Pearl River and the northern Gulf of Mexico, as characterized by flow field-flow fractionation. Mar Chem. 2010;118:119-28.

89. Bundy RM, Abdulla HAN, Hatcher PG, Biller DV, Buck KN, Barbeau KA. Ironbinding ligands and humic substances in the San Francisco Bay estuary and estuarine-influenced shelf regions of coastal California. Mar Chem. 2015;173:183-94.

90. Dulaquais G, Waeles M, Gerringa LJA, Middag R, Rijkenberg MJA, Riso R. The biogeochemistry of electroactive humic substances and its connection to iron chemistry in the North East Atlantic and the Western Mediterranean Sea. J Geophys Res Ocean. 2018;123:5481-99.

91. Hassler CS, van den Berg CMG, Boyd PW. Toward a regional classification to provide a more inclusive examination of the ocean biogeochemistry of ironbinding ligands. Front Mar Sci. 2017:4:19.

92. Gauglitz JM, Boiteau RM, McLean C, Babcock-Adams L, Mcllvin MR, Moran DM, et al. Dynamic proteome response of a marine Vibrio to a gradient of iron and ferrioxamine bioavailability. Mar Chem. 2021;229:103913.

93. Velasquez IB, Ibisanmi E, Maas EW, Boyd PW, Nodder S, Sander SG. Ferrioxamine siderophores detected amongst iron binding ligands produced during the remineralization of marine particles. Front Mar Sci. 2016;3:172.

94. Cordero OX, Ventouras LA, DeLong EF, Polz MF. Public good dynamics drive evolution of iron acquisition strategies in natural bacterioplankton populations. Proc Natl Acad Sci USA. 2012;109:20059-64.

95. Barbeau K, Rue EL, Bruland KW, Butler A. Photochemical cycling of iron in the surface ocean mediated by microbial iron(III)-binding ligands. Nature 2001;413:409-13.

96. Völker C, Tagliabue A. Modeling organic iron-binding ligands in a threedimensional biogeochemical ocean model. Mar Chem. 2015;173:67-77.

97. Nusca TD, Kim Y, Maltseva N, Lee JY, Eschenfeldt W, Stols L, et al. Functional and structural analysis of the siderophore synthetase AsbB through reconstitution of the petrobactin biosynthetic pathway from Bacillus anthracis. J Biol Chem. 2012;287:16058-72.

98. Hamana K, Matsuzaki S. Widespread occurrence of norspermidine and norspermine in eukaryotic algae. J Biochem. 1982;91:1321-8.

99. Hamana K. Polyamine distribution patterns within the families Aeromonadaceae, Vibrionaceae, Pasteurellaceae, and Halomonadaceae, and related genera of the gamma subclass of the Proteobacteria. J Gen Appl Microbiol. 1997:43:49-59.

100. Michael AJ. Polyamines in eukaryotes, bacteria, and archaea. J Biol Chem. 2016:291:14896-903.

101. Gärdes A, Triana C, Amin SA, Green DH, Romano A, Trimble L, et al. Detection of photoactive siderophore biosynthetic genes in the marine environment. BioMetals 2013;26:507-16.

\section{ACKNOWLEDGEMENTS}

We would like to thank Andrew Allen at the J. Craig Venter Institute for providing $A$. macleodii ATCC 27126, Rachel Diner, Erin Garza, and Vincent Bielinski at the J. Craig Venter Institute for support in generating the $\triangle a s b B:: \mathrm{km}^{r}$ cell line, Lauren Hearn, Peter Morton, and William Landing at Florida State University for processing and providing the Arizona Test Dust as well as providing valuable feedback on this manuscript, the Captain and crew of the R/V Ka'imikai-O-Kanaloa, Chief Scientist Ginger Armbrust at the University of Washington, and Ruifeng Zhang for the collection of the dissolved siderophore samples on Gradients 1.0, and Rachael Chan at the Art Center College of Design for the illustration in Fig. 5. Finally, we thank the three anonymous reviewers who significantly improved the quality of this paper. 
This work was supported by an NSF Graduate Research Fellowship and Simons Foundation award \#729162 to LEM, NSF OCE-1558453 and NSF OCE-2049299 to CLD, NSF OCE-1558841, and NSF OCE-2049301 to KAB, and Simons Foundation award \#426570 to RMB and JP.

\section{COMPETING INTERESTS}

The authors declare no competing interests.

\section{ADDITIONAL INFORMATION}

Supplementary information The online version contains supplementary material available at https://doi.org/10.1038/s41396-021-01065-y.

Correspondence and requests for materials should be addressed to L.E.M.

Reprints and permission information is available at http://www.nature.com/ reprints
Publisher's note Springer Nature remains neutral with regard to jurisdictional claims in published maps and institutional affiliations.

(i) Open AccessThis article is licensed under a Creative Commons Attribution 4.0 International License, which permits use, sharing, adaptation, distribution and reproduction in any medium or format, as long as you give appropriate credit to the original author(s) and the source, provide a link to the Creative Commons licence, and indicate if changes were made. The images or other third party material in this article are included in the article's Creative Commons licence, unless indicated otherwise in a credit line to the material. If material is not included in the article's Creative Commons licence and your intended use is not permitted by statutory regulation or exceeds the permitted use, you will need to obtain permission directly from the copyright holder. To view a copy of this licence, visit http://creativecommons. org/licenses/by/4.0/.

(c) The Author(s) 2021 